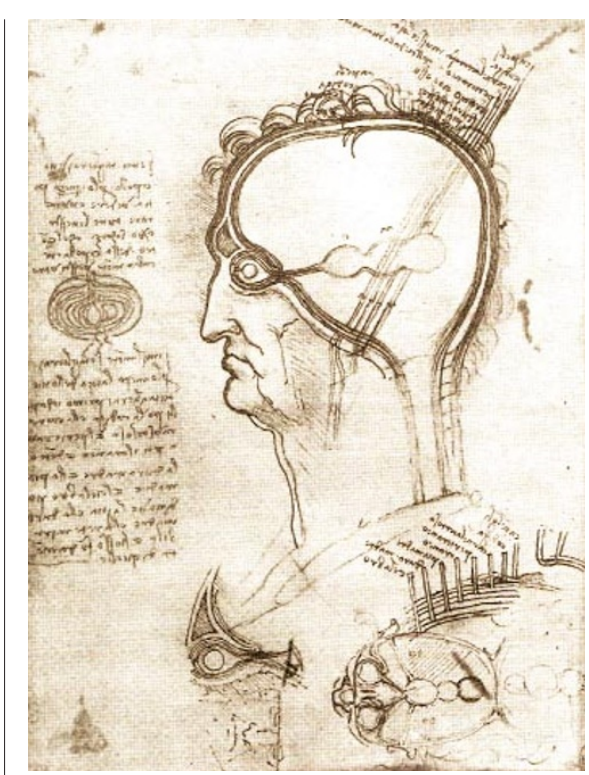

Believing is seeing: here, even Leonardo drew what he thought he knew, rather than what he saw.

be the crucial organ of cognition, the search was on for assigning different functions to distinct regions. Are the ventricles the substrate of computation, and the cerebral cortex mere protective covering? If the cortex is the seat of 'higher' functions, are those offices equipotentially distributed throughout the cortex? If there is a brain 'centre' for vision, is it localized in parietal or in occipital cortex?

Gross expertly leads the reader through the highways and byways of how and why better answers to such questions become available. In a story that is never less than fascinating, a few gems stand out. It is well known that Aristotle argued that the brain plays a subordinate role in the heart-brain system responsible for sensation, intelligence and movement. Gross's account of how Aristotle could find this view both rationally plausible and empirically valid is superb. Likewise, Gross performs a mitzvah in remembering the early brilliance, mature achievement and tragic fate of the Polish sensory neurophysiologist Adolf Beck.

Another essay, primarily concerned with the visual system, discusses Leonardo da Vinci's neuroanatomical illustrations. The chapter is a salutary reminder that not even the greatest of draughtsmen could entirely avoid drawing what he (thought he) knew, rather than what he actually saw. An intriguing digression on the irony of how "Leonardo, who presumably easily read his own left-right reversed writing, found it inconceivable that the brain could interpret an inverted image" is all too short.

The fame of Leonardo provides a striking contrast to the obscurity (within neuroscience, at least) of another all-round genius, Emanuel Swedenborg, to whom Gross devotes a very welcome chapter. Swedenborg "read widely about the brain in the biological and medical literature of the day". His extensive writings on the brain and sense organs turn out to be observationally more accurate and theoretically more profound than those of any other eighteenth-century scholar. Gross attributes the neglect of Swedenborg to the fact that he failed to publish (in relevant places). This is no doubt correct, and should serve as a dire warning to us all. But one also suspects that Swedenborg's invention of a new religion - the New Jerusalem Church — counted against him when research income per head of staff was calculated: the Swedish government paid him to be Inspector of Mines, not to worry about the biological bases of the soul.

The final chapter (on how vision purportedly took over more and more of the brain) takes us from the end of the nineteenth century (Paul Fleschig's work on visual association cortex) to the 'what' and 'where' pathways of current neuroscience. Although Gross can still find mistakes aplenty in this period, even he finds it hard to suppress the urge to rejoice that now, at last, we've got it right.

The reader should keep the dust-jacket, on which Torsten Wiesel writes of his hope that Gross's magnificent volume will "encourage today's neuroscientists to search carefully for their own misconceptions and follies". Gross concludes with a warning against the reification of neuropsychological categories. But the stories that he tells suggest that the reification of neuroanatomical structures is a greater danger.

John C. Marshall is at the Neuropsychology Unit, University Department of Clinical Neurology, Radcliffe Infirmary, Woodstock Road, Oxford OX2 6HE, UK.

\section{A piece of the true Feynman}

\section{The Meaning of it All: Thoughts of a Citizen Scientist}

by Richard P. Feynman

Addison Wesley: 1998. Pp.122. £12.99, \$22

\section{Stephen Battersby}

A small volume has appeared that transcribes a lecture series given by Richard Feynman. This is not an unfamiliar happening; new bits of Feynmania appear quite frequently, and I suppose we should be as used to the cult of Feynman as we are to other celebrity cults. Then again, because Feynman is set up as a thinker and guru, even as a prophet, perhaps his status should be more carefully examined.

Here he sets out to tackle science's relations with politics, religion and everyday society. If Feynman was a prophet, I suppose this was his sermon on divine uncertainty the uncertainty that allows the scientific process to work. Knowledge can progress, says Feynman, only if people have open minds and test their ideas. So far so good.

Not surprisingly, dogma comes in for a bashing. Feynman is relatively gentle with religion, only pointing out that it is hard to reconcile a culture of doubt (science) with one of faith. He is much fiercer with political dogma, especially with the communism of the former Soviet Union, so much less friendly to new ideas than the uncertaintyenshrining democracy of the United States. Although the words he uses are measured, he admits to becoming over-emotional at this point. Well, this was 1963 , only months after the Cuban missile crisis, so perhaps it is understandable.

But then we hit a snag: in print, and unedited, Feynman doesn't always make sense. In one crucial passage he tries to argue that "ethical values lie outside the scientific realm". This must be a comforting opinion for someone who worked on the bomb, but he is on controversial ground, and here most of all he reveals himself to be surprisingly inarticulate. Here is one whole argument for the separation of science and ethics: "First, in the past there were conflicts. The metaphysical positions have changed, and there have $[$ sic] been practically no effect on the ethical views. So there must be a hint that there is an independence." Eh? Well, I catch the drift, but one would hope for more than that. Ordinary people have this sort of vague insight all the time; what one wants from a guru is a little more intellectual clarity - or at least more memorable phrasing.

It does get better. In the last lecture, he has a go at the sort of everyday stupidity that comes of not thinking scientifically, especially from having a poor sense of probability. People justify their beliefs in flying saucers, astrology and faith healing, for example, because these things are "possible". These may be soft targets but they always need attacking, and it is fun to watch them being hit so hard. Even Feynman's arrogance can be endearing here, and one can imagine his tone of exasperation when he said "the number of things that are possible is not fully appreciated by the average individual".

The Feynman of these lectures is certainly sensible and amusing, but not inspirational. Don't visit him for sacred wisdom. $\square$ Stephen Battersby is an assistant editor of Nature.

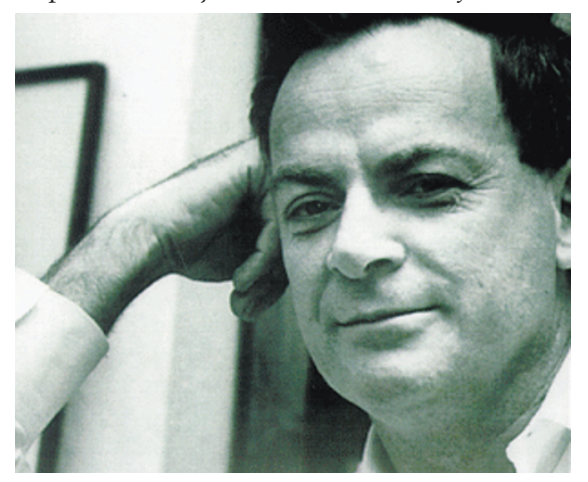

Feynman: surprisingly inarticulate. 